\title{
The apoptotic effect of polysaccharides with specific molecular weight extracted from Inonotus obliquus on HT-29 colon cancer cells
}

Xue Han ( $\nabla$ xhan@hit.edu.cn )

Harbin Institute of Technology

\section{Sainan Zhao}

Harbin Institute of Technology

\section{Yu Wang}

Harbin Institute of Technology

Jialei Sun

Harbin Institute of Technology

Shiwei Chen

Harbin Institute of Technology

\section{Research}

Keywords: Inonotus obliquus polysaccharides, colorectal cancer, apoptosis, mitochondrial pathway

Posted Date: September 3rd, 2020

DOl: https://doi.org/10.21203/rs.3.rs-38256/v2

License: (9) This work is licensed under a Creative Commons Attribution 4.0 International License. Read Full License 


\section{Abstract}

Background: Recently, natural products, particularly Inonotus obliquus (I. obliquus), have attracted lots of attention due to their effective anticancer effects with relatively low toxicity.

Results: I. obliquus polysaccharides (IOP) with different molecular weights were obtained by filtering the aqueous extract through fractional membrane. IOP60b (10 kDa $\leq$ molecular weight $\leq 30 \mathrm{kDa}$ ) with the highest yield and inhibition ratio of HT-29 cancer cells was chosen to evaluate the apoptotic effect on HT29 cancer cells. After treated with different concentrations of IOP60b, morphological changes including cell shrinkage and nuclear condensation and DNA fragmentation of HT-29 cancer cells were observed. In addition, the proportions of cells in early apoptosis and late apoptosis were significantly $(p<0.05)$ increased in a dose-dependent manner. To further explore the underlying mechanism, RT-PCR and Western blotting were employed. Results indicated that both Bcl-2 family and Caspase family were involved in the regulation process of apoptosis and IOP60b induced cellular apoptosis via upregulation of $\mathrm{Bax} / \mathrm{Bcl}-2$ ratio and activation of Caspase-3.

Conclusion: These data suggested that IOP60b could be a potential candidate for the clinical prevention and treatment of colorectal cancer.

\section{Introduction}

Colorectal cancer is one of the most common global gastrointestinal malignant tumors, which has caused great concern worldwide particularly in western and developed nations due to its great threat to human being health ${ }^{1}$. In fact, the incidence of colon cancer is closely related to the personal lifestyle. As far as we know, the incidence and death rates from colon cancer have been on the rise as people's living standards have improved and their eating habits have changed in the last few decades ${ }^{2}$. At present, surgical resection, radiotherapy and chemotherapy are dominant methods applied for colon cancer treatment. However, nonnegligible side effects brought by those methods such as hair loss, bleeding, diarrhea and immunosuppression ${ }^{3}$ significantly limit their applications. Therefore, natural products are regarded as promising drugs for tumor therapy resulting from their effective anticancer effects with relatively low toxicity ${ }^{4}$.

Inonotus obliquus (I. obliquus), a white rot fungus, has been widely used as a folk remedy in Russia since the 16 th century ${ }^{5}$ for its non-toxic effects on treating gastrointestinal cancers and digestive system diseases ${ }^{6}$. Polysaccharides, as the main bioactive constituents of $I$. obliquus $^{7}$, have triggered much attention in recent years due to their biological effects, including anti-cancer ${ }^{8}$, anti-inflammatory ${ }^{9}$, antioxidation ${ }^{10}$, hypolycemic effect ${ }^{11}$, and immuno-stimulating ${ }^{12}$. Moreover, multiple researches have proved that polysaccharides extracted from I. obliquus have cytotoxicity on multiple tumor cells, such as human stomach carcinoma ${ }^{13,14}$, human hepatoma ${ }^{14,15}$, human lung carcinoma $14,16,17$, kidney adenocarcinoma ${ }^{14}$, human breast adenocarcinoma ${ }^{14}$, human ovary adenocarcinoma ${ }^{14}$, human endometrial epithelial cells ${ }^{14}$, murine melanoma cells ${ }^{14,16,18}$, human T lymphadenoma jurkat cells ${ }^{15}$ et 
al.. Previous research reported that extracts of $I$. obliquus by water and ethanol could directly inhibit the proliferation of colon cancer cells, and they were mainly composed of polysaccharides and proteins with polysaccharides accounted for the largest proportion $7,19,20$. A preliminary deduction is that polysaccharides from I. obliquus play a major role in its anticancer effects on colon carcinoma. Few studies were conducted regarding the effects of polysaccharides with specific molecular weight extracted from I. obliquus on colon cancer. In addition, studies on the mechanism of anti-colon cancer of I. obliquus showed that the aqueous extract of $I$. obliquus induced apoptosis of colon cancer cells by downregulating Bcl-2 protein expression and up-regulating Bax and Caspase-3 protein expression ${ }^{21}$. While Lee et al. ${ }^{22}$ found that the ethanol extract of $I$. obliquus inhibited colon cancer by arresting the cell cycle G1 phase. There is no consistent conclusion about how polysaccharides from I. obliquus exactly work on HT-29 colon cancer. Therefore, the current study was carried out to reveal the anticancer effects of polysaccharides with specific molecular weight isolated from I. obliquus and further explore the related mechanism.

\section{Material And Methods}

\subsection{Materials and reagents}

The fruiting bodies of I. obliquus were collected from Changbai Mountain, Jilin, China. Human colon carcinoma cells HT-29 were obtained from Cancer Hospital Chinese Academy of Medical Sciences, Beijing, China. Cells were cultured in RPMI-1640 medium supplemented with 10\% fetal bovine serum (FBS) at $37{ }^{\circ} \mathrm{C}$ in a humidified atmosphere with $5 \% \mathrm{CO}_{2}$. All reagents used for cell culture were from Hyclone (USA). Cell Counting Kit-8 (CCK-8) was purchased from Dojindo (Japan). Tissue DNA Kit was purchased from Solarbio (Beijing, China). Annexin V-FITC Apoptosis Detection Kit was purchased from Njjcbio (Nanjing, China). Antibodies to Bcl-2, Bax, Caspase-3 and $\beta$-actin were obtained from Wanleibio (Shenyang, China).

\subsection{Extraction, purification, and fraction of polysaccharides}

The crude water-soluble polysaccharides were extracted from I. obliquus samples (CIOP) with distilled water at $60^{\circ} \mathrm{C}$ according to the method outlined by Xu et al ${ }^{23}$. After removal of the protein by using the Sevag reagent, the CIOP solution was mixed with $95 \%(\mathrm{v} / \mathrm{v})$ ethanol to reach a final concentration of $60 \%$ ( $\mathrm{v} / \mathrm{v})$ and stored at $4^{\circ} \mathrm{C}$ overnight. After centrifugation, dialysis and freeze drying, the precipitate was termed as IOP60. $10 \mathrm{mg} / \mathrm{mL}$ IOP60 solution was prepared, filtered through a $0.22 \mu \mathrm{m}$ membrane, and assembled with ultrafiltration centrifuge tubes (Merck Millipore Amicon $\left.{ }^{T M}\right)$. After centrifugation and freeze drying, fractions were collected and termed as IOP60a (3 kDa $\leq$ molecular weight $\leq 10 \mathrm{kDa}$ ), IOP60b (10 $\mathrm{kDa} \leq$ molecular weight $\leq 30 \mathrm{kDa}), \operatorname{lOP} 60 \mathrm{c}$ (30 kDa $\leq$ molecular weight $\leq 50 \mathrm{kDa})$, IOP60d (50 $\mathrm{kDa} \leq$ molecular weight $\leq 100 \mathrm{kDa}$ ), and IOP60e (molecular weight $\geq 100 \mathrm{kD}$ ), respectively. Their yields were calculated based on the weight of each fraction to the weight of the total IOP60. 
HT-29 cells were seeded for $12 \mathrm{~h}$ in 96 -well plates $\left(2 \times 10^{6} \mathrm{cells} / \mathrm{mL}\right)$, and then treated with $1.25 \mathrm{mg} / \mathrm{mL}$ polysaccharide fraction (IOP60a, IOP60b, IOP60c, IOP60d, IOP60e) for 24 h, respectively. CCK-8 assay was used to detect the cell viability according to the manufacturer's protocol ${ }^{24}$. All determinations were done in six duplicates. The inhibition ratio of tumor cell proliferation was calculated according to the formula below:

\section{See formula 1 in the supplementary files.}

Where As, Ac and Ab were the absorbance of treated cells, untreated cells, and the control group, respectively.

\subsection{Observation of cell morphology}

HT-29 cells $\left(2 \times 10^{6}\right.$ cells per well) were seeded in 6 -well plates for $24 \mathrm{~h}$ and treated with different concentrations of IOP $60 \mathrm{~b}(0,0.625,1.25,2.5,5,10 \mathrm{mg} / \mathrm{mL})$ for $48 \mathrm{~h}$. After that, cells were fixed with $4 \%$ formaldehyde in PBS for 10 min, and then subjected to optical microscopy (Olympus BX51, Japan).

\subsection{DNA fragmentation analysis}

IOP60b-treated (48 h) HT-29 cells were washed and resuspended in $1 \mathrm{~mL}$ PBS. Total DNA of cells was extracted according to the manufacturer's instructions. The extracted DNA samples were run on the 1.2\% agarose gel in 1XTAE buffer. After that, the gel was visualized with a UV light by Gel Imaging System and photographed.

\subsection{Cell apoptosis and Cell cycle analysis by flow cytometry}

The percentage of specific apoptotic cells was determined by flow cytometry according to the manufacturer's procedure. Briefly, HT-29 cells were plated in a 6-well plate $\left(1 \times 10^{5} \mathrm{cells} / \mathrm{mL}\right)$ and treated with different concentrations of IOP60b $(0.625,1.25,2.5,5,10 \mathrm{mg} / \mathrm{mL})$ for $48 \mathrm{~h}$. Cells were collected and washed twice in cold PBS, and then resuspended in $500 \mu \mathrm{L}$ binding buffer containing $5 \mu \mathrm{L}$ Annexin VFITC and $5 \mu \mathrm{L}$ propidium iodide (PI) for $10 \mathrm{~min}$ in the dark, finally analyzed using Millipore guava easy Cyte $^{\mathrm{TM}}$ flow cytometer (Millipore, USA) and Guavasoft 3.1.1 software.

Similarly, HT-29 cells were first plated in a 6-well plate $\left(1 \times 10^{5}\right.$ cells $\left./ \mathrm{mL}\right)$ and treated with different concentrations of IOP $60 \mathrm{~b}(0.625,1.25,2.5,5,10 \mathrm{mg} / \mathrm{mL})$ for $48 \mathrm{~h}$ and then used for cell cycle analysis. Cells were centrifuged at $12000 \times \mathrm{g}$ for $5 \mathrm{~min}$ and then fixed with $70 \%(\mathrm{v} / \mathrm{v})$ ethanol and stored at $4{ }^{\circ} \mathrm{C}$ overnight. The precipitate of cells was washed with PBS, treated with $100 \mu \mathrm{L}$ RNase, and incubated for 30 min at $37{ }^{\circ} \mathrm{C}$. After centrifugation, cells were incubated with $\mathrm{PI}$ at $4{ }^{\circ} \mathrm{C}$ for another $30 \mathrm{~min}$ in the dark. Cell cycle distributions were detected by flow cytometry and analyzed using ModFit LT 5.0 software.

\subsection{Real-time quantitative RT-PCR analysis}


HT-29 cells $\left(5 \times 10^{5}\right.$ cells $\left./ \mathrm{mL}\right)$ were seeded in 6 -well plates and treated with $5 \mathrm{mg} / \mathrm{mL}$ IOP60b for $0 \mathrm{~h}, 24 \mathrm{~h}$, $48 \mathrm{~h}, 72 \mathrm{~h}$, respectively. Total RNA was extracted using total RNA extraction kit (GeneMark ${ }^{\mathrm{TM}}$ ) and then reversed to cDNA by using the All-in-One ${ }^{\text {TM }}$ First-Strand cDNA Synthesis Kit (GeneCopoeia, USA) according to the manufacturer's protocol. Real-time PCR was performed with 2×Es Taq MasterMix (Dye) (CWBIO, Beijing, China). The following primers (Sangon Biotech, Shanghai, China) were used for amplification: Bcl-2 forward 5'-CAG CTG CAC CTG ACG CCC TT-3' and reverse 5'-GCC TCC GTT ATC CTG GAT CC-3'; Bax forward 5'-TTC TGA CGG CAA CTT CAA CTG-3' and reverse 5'-TGA GGA GGC TTG AGG AGT CT-3'; Caspase-3 forward 5'-ACA CAG TAT GGC GGC AGA G-3' and reverse 5'-AGA CAG GCA ACA GAG CAC AT-3'; $\beta$-actin forward 5'-CCT CTA TGC CAA CAC AGT GC-3' and reverse 5'-ATA CTC CTG CTT GCT GAT CC-3'.

\subsection{Western blotting}

HT-29 cells were harvested and lysed after treated with IOP60b for desired time ( $0 \mathrm{~h}, 24 \mathrm{~h}, 48 \mathrm{~h}, 72 \mathrm{~h})$. Total proteins were extracted using a Total Protein Extraction Kit (Wanleibio, China), and the protein concentration was determined using a BCA Protein Assay Kit (Wanleibio, China) according to the manufacturer's protocol. Equal amounts of proteins were boiled for 5 min and separated by SDS-PAGE, then transferred onto a PVDF membrane. Blocking of non-specific binding was achieved by placing the membrane in a dilute solution of $5 \%$ skim milk powder in tris-buffered saline (TBS) for $1 \mathrm{~h}$. After blocking, a diluted solution of primary antibody (Bcl-2, Bax, Caspase-3 and $\beta$-actin) at a concentration of 1:500 was incubated with the membrane overnight at $4{ }^{\circ} \mathrm{C}$ under gentle agitation. After that, the primary antibody was diluted with TBST wash buffers. The membrane was rinsed to remove unbound primary antibody, followed by incubation with a dilute solution of secondary antibody (HRP-labeled goat anti-rabbit lg G) at a concentration of $1: 5000$ for $45 \mathrm{~min}$ at $37^{\circ} \mathrm{C}$. After a final wash of membrane with TBST buffers, the Electrochemilu-minescence $(E C L)$ reagent was used to measure the chemiluminescence intensity. Tand intensities were quantitated using Gel-Pro-Analyzer software.

\subsection{Statistical analysis}

All the measurements and analyses were carried out in triplicate. The experimental results were presented as means of three determinations \pm SD (standard deviation). Origin (version 8.5) and SPSS (version 16.0) with Tukey's multiple comparisons were used for the statistical and graphical evaluation. The statistical significance of mean differences was based on $p$-Values of $<0.05$.

\section{Results And Discussion}

3.1. Yields and inhibition ratios of polysaccharides with different molecular weights

Results in Figure 1 showed that the yield of IOP60b (10 kDa $\leq$ molecular weight $\leq 30 \mathrm{kDa}$ ) significantly higher than that of any other polysaccharide fraction $(P<0.05)$. As for the inhibition ratios of HT-29 colon cancer cells , IOP60b (10 kDa $\leq$ molecular weight $\leq 30 \mathrm{kDa}$ ) exhibited the highest value, reaching $61.9 \%$, which was followed by IOP60a (3 kDa $\leq$ molecular weight $\leq 10 \mathrm{kDa}$ ), while IOP60e with the largest 
molecular weight $₫ \geq 100 \mathrm{kDa} \bigotimes$ only inhibited $28.3 \%$ cancer cells. It has been shown that polysaccharides with smaller molecular weight generally had higher biological activity 14,25 , which was consistent with our results. Therefore, IOP60b was chosen to further explore its effects on apoptosis of HT-29 colon cancer cells and the underlying mechanism.

\subsection{IOP60b induced morphological changes and DNA fragmentation}

Optical microscopy was used to observe morphological changes of HT-29 cells after treated with IOP60b $(0,0.625,1.25,2.5,5$ and $10 \mathrm{mg} / \mathrm{mL})$ for $48 \mathrm{~h}$. As demonstrated in Figure 2, cells in the control group adhered to the wall and grew vigorously with fusiform or polygonal cell bodies and large nuclei. Besides, their cytoplasm was uniform and transparent with high transmittance. After 48 hours of IOP60b treatment, the number of adherent cells decreased and with the cell contents increased, the transmittance was reduced. Meanwhile, the cells became shrunk or even shattered and the nuclei were concentrated, therefore, the cell volume was much smaller than that in control group. In addition, as the concentration of IOP60b increased, the morphological changes became more pronounced.

Agarose gel electrophoresis was used to detect the nuclear DNA from HT-29 cells. As shown in Figure 3, the untreated cells represented by Lane A showed normal chromosomal DNA with no DNA ladder, while DNA isolated from HT-29 cells treated with different concentrations of IOP60b for $48 \mathrm{~h}$ (Lane B-F) was all degraded into giant DNA fragments, and the DNA ladder phenomenon became more apparent as the increasing concentrations of IOP60b. As we all know, apoptosis is an extremely important process to maintain cellular homeostasis, accompanied by specific changes in cell morphology such as cell shrinkage, membrane blebbing, nuclear condensation and inter-nucleosomal DNA fragmentation ${ }^{1}$. Therefore, combined the cell morphological changes with nuclear DNA fragmentation, it is speculated that IOP60b may induce colon cancer HT-29 cell death through the apoptotic pathway.

\subsection{IOP60b induced apoptosis in HT-29 cells}

To evaluate whether the IOP60b treatment $(0,0.625,1.25,2.5,5$ and $10 \mathrm{mg} / \mathrm{mL})$ for $48 \mathrm{~h}$ in HT-29 cells was associated with apoptosis, annexin V-FITC/PI apoptosis assay ${ }^{26}$ was conducted by flow cytometry. Results in Table 1 demonstrated that as the concentration of IOP $60 \mathrm{~b}$ increased from $0.625 \mathrm{mg} / \mathrm{mL}$ to 10 $\mathrm{mg} / \mathrm{mL}$, the percentages of cells in early apoptosis compared with the negative control group increased by $3.15 \%-6.97 \%$, and the percentage of cells in late apoptosis significantly increased ranging from $10.20 \%$ to $28.46 \%(P<0.05)$. In addition, the total number of apoptotic cells in HT-29 treated with 0.625 , $1.25,2.5,5$ and $10 \mathrm{mg} / \mathrm{mL}$ IOP60b increased by $13.35 \%, 21.64 \%, 27.68 \%, 34.74 \%$ and $35.43 \%$, respectively. Obviously, IOP60b resulted in increased proportions of cells in early apoptosis and late apoptosis in a dose-dependent manner. Thus, we can conclude that IOP60b are able to significantly inhibit cell proliferation by inducing apoptosis of colon cancer HT-29 cells.

\subsection{IOP60b triggers cell cycle arrest in HT-29 cells}


The cell-division cycle is a vital process which consists of four distinct phases: $\mathrm{G} 1$ phase, S phase (synthesis), G2 phase (collectively known as interphase) and M phase (mitosis or meiosis). Deregulation of the cell cycle is the most common abnormality in human cancer. Cells which are actively undergoing cell cycles are targeted in cancer therapy as their DNA is exposed during cell division and hence susceptible to damage by drugs or radiation ${ }^{27}$. In the present study, flow cytometry was used to investigate the cell cycle distribution treated with different concentrations $(0.625 \rrbracket 1.25 \llbracket 2.5 \llbracket 5$ and 10 $\mathrm{mg} / \mathrm{mL}$ ) of IOP60b for $48 \mathrm{~h}$. In the presence of IOP60b, we observed a dose-dependent increase in the percentage of cells in G0/G1 phase accompanied by a corresponding reduction in the percentages of cells in $\mathrm{S}$ and G2/M phases (Table 1). These data suggest that IOP60b induced G0/G1 phase arrest in HT29 cells, which was in agreement with the results of Youn et al ${ }^{28}$. The mechanism by which polysaccharides from I. obliquus inhibits cell proliferation and arrests cell cycle could be explained as follows: polysaccharides can inhibit ribosome synthesis in G0/G1 phase, thereby inhibiting cell protein synthesis and reducing mitosis, leading to cell proliferation. On the other hand, the polysaccharides interferes with the synthesis of DNA by inhibiting the synthesis of RNA and protein, thereby arresting the cells in the G0/G1 phase and ultimately inhibiting cell proliferation ${ }^{29}$.

\subsection{Effects of IOP60b on Bcl-2, Bax, and Caspase-3 expressions in HT-29 colon cancer cells}

Increasing evidence has identified natural product might control cancer via the direct or indirect modulation of apoptosis-related genes ${ }^{30}$. RT-PCR was used to investigate the expression of caspase-3, Bax, Bcl-2, and Bad at different time points. As shown in Figure 4, after $0 \mathrm{~h}, 24 \mathrm{~h}, 48 \mathrm{~h}$ and $72 \mathrm{~h}$ treatment with $5 \mathrm{mg} / \mathrm{mL}$ IOP60b, the expression level of Bcl-2 gene in the drug-exposed groups was significantly decreased, whereas the level of Bax gene was dramatically increased in a time-dependent manner compared to the negative control $(P<0.05)$. As we all know, $\mathrm{Bcl}-2$ plays a role of anti-apoptosis in the $\mathrm{Bcl}-2$ family, while Bax plays a role of pro-apoptotic ${ }^{31}$, and the Bax/Bcl-2 ratio was often used as an index of apoptosis $^{32}$. Therefore, we deduced that IOP60b promotes HT-29 colon cancer cells apoptosis by regulating $\mathrm{Bax} / \mathrm{Bcl}-2$ ratio. Furthermore, we examined whether caspase-3 activity would change with

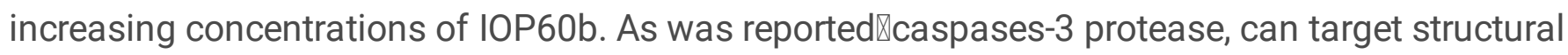
substrates and induce cancer cell breakdown and DNA fragmentation ${ }^{4}$ and its activation marks the irreversible stage of apoptosis ${ }^{33}$. Results in Figure 4 showed that caspase-3 activity increased significantly at all time-points $(P<0.05) \llbracket$ which proved that caspase- 3 also played an important role in the process of HT-29 colon cancer cells apoptosis induced by IOP60b. This conclusion was consistent with the point mentioned by Cheng-Chih Tsaia et.al. ${ }^{34}$ who investigated apoptosis effects of $I$. obliquus extract on HCT-116 cell line.

\subsection{Effects of IOP60b on Bcl-2, Bax, and Caspase-3 expressions in HT-29 cells}

To further determine the role of the Bcl-2 families and caspase-3 played in IOP60b mediated apoptosis, western blot analysis was used to detect the changes in the levels of $\mathrm{Bcl}-2$, Bax and a caspase. The expression of $\beta$-action was used as a loading control. As shown in Figure 5, similar to the RT-PCR results, 
there was a significant decrease in the expression levels of $\mathrm{Bcl}-2$ protein $(P<0.05)$, while significant increase in Bax and Caspase-3 in the IOP60b-treated groups compared with the negative control $(P<0.05)$. Besides, these trends were more pronounced as the treatment time increased from $0 \mathrm{~h}$, to $72 \mathrm{~h}$ indicating that IOP60b induced cell apoptosis of HT-29 cells in a time-dependent manner.

An article by Lee et al. ${ }^{21}$ mentioned that aqueous extracts from the fruiting bodies of I.obliquus could inhibit HT-29 colorectal cancer cells, and the anti-apoptotic protein Bcl-2 was found to be inhibited and the pro-apoptotic protein Bax was promoted, at the same time, the levels of procaspase-3 showed a decreasing trend, implying that procaspase- 3 underwent cleavage and activation into caspase-3, which in turn affected apoptosis in HT-29 cells. Youn et al. ${ }^{35,36}$ employed Western blotting to analyze the protein expression of procaspase-3 in HepG2 liver cancer cells which were treated with aqueous extracts of $I$. obliquus, results showed that as the concentration of I. obliquus increases, there was a significant decrease in procaspase-3. It was explained that extracts from I. obliquus fruiting bodies could aid in procaspase- 3 activation into caspase-3. Nomura et al. ${ }^{37}$ also found that inotodiol, a lanostane triterpenoid from I. obliquus can inhibit P388 leukemia cells through caspase-3 activation.

In this case, our results are in agreement with these previous studies wherein extracts of I. obliquus have been reported to exhibit anticancer effects via upregulating Bax, Caspase-3 activity and downregulating Bcl-2 activity ${ }^{19,20}$.That is to say, polysaccharides from I. obliquus induce apoptosis in HT-29 cells through the mitochondrial pathway.

\section{Conclusions}

In the present study, polysaccharides with different molecular weights were successfully purified from IOP60 with ultrafiltration centrifuge tubes. IOP60b (10 kDa $\leq$ molecular weight $\leq 30 \mathrm{kDa}$ ) was selected to verify the effects and mechanisms of apoptosis because it had the highest yield and inhibition ratio of HT-29 colon cancer cells. It was observed that IOP60b induced morphological changes and DNA ladder phenomenon of HT-29 colon cancer cells. The results of flow cytometry indicate that IOP60b induced cells in early apoptosis and late apoptosis increased in a dose-dependent manner and significant G0/G1 phase arrest in HT-29 cells. More so, according to the RT-PCR and western blot results, it could be preliminarily inferred that, IOP60b induced cellular apoptosis of HT-29 cells through the mitochondrialmediated apoptosis pathway in which the expression of Bax and Caspase-3 were upregulated and the expression of $\mathrm{Bcl}-2$ was downregulated. These data suggested that polysaccharides with specific molecular weight ( $10 \mathrm{kDa} \leq$ molecular weight $\leq 30 \mathrm{kDa}$ ) could significantly inhibit the growth of HT-29 cells and induce apoptosis. IOP60b might be the potential candidate for the clinical prevention and treatment of colorectal cancer, while the underlying mechanism still needs further study.

\section{Declarations}

Ethics approval and consent to participate: This manuscript does not report on or involve any animals, humans, human data, human tissue or plants. 
Consent for publication: This manuscript does not contain data from any individual person.

Availability of data and materials: Not applicable.

Competing interests: The authors declare that they have no competing interests in this section.

Funding: This work was financially supported by national key research and development program (2018YFC1604305-01), national natural science foundation of China (31972972), and the national science foundation of Heilongjiang province of China (C2018033).

Authors' contributions: The author of Xue Han design the experience and revise the manuscript.

The author of Sainan Zhao analyzed data regarding the hematological disease and the transplant.

The author of Yu Wang and Jialei Sun do the experiment

The author of Shiwei Chen is a major contributor in writing the manuscript. All authors read and approved the final manuscript.

Acknowledgements: We would like to express our gratitude to Prof. Lanwei Zhang for his support, particularly for providing facilities to perform this work. Never forget why you started, and your mission can be accomplished.

\section{Abbreviations}

\begin{tabular}{ll} 
abbreviations & Full name \\
\hline I. obliquus & Inonotus obliquus \\
\hline FBS & fetal bovine serum \\
\hline CCK-8 & Cell Counting Kit-8 \\
\hline CIOP & crude water-soluble polysaccharides \\
\hline PI & propidium iodide \\
\hline TBS & tris-buffered saline \\
\hline ECL & Electrochemilu-minescence
\end{tabular}


1. W. Cheng, J. Ren, D. Jing and C. Wang, Anti-tumor role of Bacillus subtilis fmbJ-derived fengycin on human colon cancer HT29 cell line, Neoplasma, 2016, 63.

2. H. Yuan, X. Zhu, D. Chen, W. Wang, S. Meng and J. Wang, Effects of dual modified resistant indica rice starch on azoxymethane-induced incipient colon cancer in mice, Exp. Ther. Med., 2017, 13, 2036.

3. E. Bagheri, F. Hajiaghaalipour, S. Nyamathulla and N. A. Salehen, Ethanolic extract of Brucea javanica inhibit proliferation of HCT-116 colon cancer cells via caspase activation, Rsc Advances, 2018, 8, 681-689.

4. H. Zhu, G. Lv, Q. Qu, J. Xu, L. Zhang and Y. Zhu, Thunder god vine extract exerts antiproliferative effects on growth of human colon cancer cells and inhibits colon cancer growth in xenograft mice models, South African Journal of Botany, 2018, 115, 18-23.

5. H. Niu, D. Song, H. Mu, W. Zhang, F. Sun and J. Duan, Investigation of three lignin complexes with antioxidant and immunological capacities from Inonotus obliquus, Int. J. Biol. Macromol., 2016, 86, 587-593.

6. Y. O. Kim, S. B. Han, H. W. Lee, H. J. Ahn, Y. D. Yoon, J. K. Jung, H. M. Kim and C. S. Shin, Immunostimulating effect of the endo-polysaccharide produced by submerged culture of Inonotus obliquus, Life Sci., 2005, 77, 2438-2456.

7. H. S. Lee, E. J. Kim and H. K. Sun, Ethanol extract of Innotus obliquus (Chaga mushroom) induces G1 cell cycle arrest in HT-29 human colon cancer cells, Nutr. Res. Pract., 2015, 9, 111.

8. X. Ning, Q. Luo, C. Li, Z. Ding, J. Pang and C. Zhao, Inhibitory effects of a polysaccharide extract from the Chaga medicinal mushroom, Inonotus obliquus (higher Basidiomycetes), on the proliferation of human neurogliocytoma cells, Int. J. Med. Mushrooms, 2014, 16, 29.

9. S. K. Mishra, J. H. Kang, D. K. Kim, S. H. Oh and M. K. Kim, Orally administered aqueous extract of Inonotus obliquus ameliorates acute inflammation in dextran sulfate sodium (DSS)-induced colitis in mice, J. Ethnopharmacol., 2012, 143, 524-532.

10. Y. Hu, S. Shi, L. Lu, C. Teng, S. Yu, X. Wang, M. Yu, J. Liang and J. Qu, Effects of selenizing modification on characteristics and antioxidant activities of Inonotus obliquus polysaccharide, Macromolecular Research, 2017, 25, 1-9.

11. J. Wang, C. Wang, S. Li, W. Li, G. Yuan, Y. Pan and H. Chen, Anti-diabetic effects of Inonotus obliquus polysaccharides in streptozotocin-induced type 2 diabetic mice and potential mechanism via PI3KAkt signal pathway, Biomed. Pharmacother., 2017, 95, 1669-1677.

12. C. W. Wold, C. Kjeldsen, A. Corthay, F. Rise, B. E. Christensen, J. Ø. Duus and K. T. Inngjerdingen, Structural characterization of bioactive heteropolysaccharides from the medicinal fungus Inonotus obliquus (Chaga), Carbohydrate Polymers, 2018, 185, 27.

13. L. Fan, S. Ding, L. Ai and K. Deng, Antitumor and immunomodulatory activity of water-soluble polysaccharide from Inonotus obliquus, Carbohydrate Polymers, 2012, 90, 870-874.

14. Y. O. Kim, H. W. Park, J. H. Kim, J. Y. Lee, S. H. Moon and C. S. Shin, Anti-cancer effect and structural characterization of endo-polysaccharide from cultivated mycelia of Inonotus obliquus, Life Sci., $2006,79,72-80$. 
15. Y. Chen, Y. Huang, Z. Cui and J. Liu, Purification, characterization and biological activity of a novel polysaccharide from Inonotus obliquus, Int. J. Biol. Macromol., 2015, 79, 587-594.

16. K. R. Lee, J. S. Lee, Y. R. Kim, I. G. Song and E. K. Hong, Polysaccharide from Inonotus obliquus inhibits migration and invasion in B16-F10 cells by suppressing MMP-2 and MMP-9 via downregulation of NF-kB signaling pathway, Oncol. Rep., 2014, 31, 2447-2453.

17. K. R. Lee, J. S. Lee, J. E. Song, S. J. Ha and E. K. Hong, Inonotus obliquus-derived polysaccharide inhibits the migration and invasion of human non-small cell lung carcinoma cells via suppression of MMP-2 and MMP-9, Int. J. Oncol., 2014, 45, 2533.

18. K. R. Lee, J. S. Lee, S. Lee, Y. K. Son, G. R. Kim, Y. C. Sim, J. E. Song, S. J. Ha and E. K. Hong, Polysaccharide isolated from the liquid culture broth of Inonotus obliquus suppresses invasion of B16-F10 melanoma cells via AKT/NF-kB signaling pathway, Mol. Med. Report., 2016, 14, 4429.

19. S. H. Lee, H. S. Hwang and J. W. Yun, Antitumor activity of water extract of a mushroom, Inonotus obliquus, against HT-29 human colon cancer cells, Phytotherapy Research Ptr, 2009, 23, 1784.

20. C. C. Tsai, Y. S. Li and P. P. Lin, Inonotus obliquus extract induces apoptosis in the human colorectal carcinoma's HCT-116 cell line, Biomed. Pharmacother., 2017, 96.

21. S. H. Lee, H. S. Hwang and J. W. Yun, Antitumor activity of water extract of a mushroom, Inonotus obliquus, against HT-29 human colon cancer cells, Phytotherapy research., 2009, 23(12), 1784-1789

22. H. S. Lee, E. J. Kim and S. H. Kim, Ethanol extract of Innotus obliquus (Chaga mushroom) induces G1 cell cycle arrest in HT-29 human colon cancer cells, Nutrition research and practice, 2015, 9, 111-116.

23. X. Xu, Y. Wu and H. Chen, Comparative antioxidative characteristics of polysaccharide-enriched extracts from natural sclerotia and cultured mycelia in submerged fermentation of Inonotus obliquus, Food Chem., 2011, 127, 74-79.

24. Z. Wang, Z. Xu, Z. Niu, B. Liang and J. Niu, Epieriocalyxin A Induces Cell Apoptosis Through JNK and ERK1/2 Signaling Pathways in Colon Cancer Cells, Cell Biochemistry \& Biophysics, 2015, 73, 559564.

25. I. B. Jeff, E. Fan, M. Tian, C. Song, J. Yan and Y. Zhou, In vivo anticancer and immunomodulating activities of mannogalactoglucan-type polysaccharides from Lentinus edodes (Berkeley) Singer, Central-European Journal of Immunology, 2016, 41, 47-53.

26. G. Niu and X.Y. Chen, Apoptosis imaging: beyond annexin V, Journal of Nuclear Medicine, 2010, 51, 1659-1662.

27. S. C. Tsaniras, N. Kanellakis, I. E. Symeonidou, P. Nikolopoulou, Z. Lygerou and S. Taraviras, Licensing of DNA replication, cancer, pluripotency and differentiation: An interlinked world?, Seminars in Cell \& Developmental Biology, 2014, 30, 174.

28. M. J. Youn, J. K. Kim, S. Y. Park, Y. Kim, S. J. Kim, S. L. Jin, K. Y. Chai, H. J. Kim, M. X. Cui and S. S. Hong, Chaga mushroom (Inonotus obliquus) induces G0/G1 arrest and apoptosis in human hepatoma HepG2 cells, World Journal of Gastroenterology, 2008, 14, 511-517.

29. X. H. Zhong, L. B. Wang and D. Z. Sun, Effects of inotodiol extracts from inonotus obliquus on proliferation cycle and apoptotic gene of human lung adenocarcinoma cell line A549, Chinese 
Journal of Integrative Medicine, 2011, 17, 218-223.

30. H. Suo, J. Song, Y. Zhou, Z. Liu, Y. I. Ruokun, K. Zhu, J. Xie and X. Zhao, Induction of apoptosis in HCT-116 colon cancer cells by polysaccharide of Larimichthys crocea swim bladder, Oncol. Lett., 2015, 9, 972-978.

31. P. Fatourachi, S. M. Mohammadi, B. Valipour, A. Dehnad and H. N. Charoudeh, Extracted metabolite from Streptomyces Levis ABRIINW111 altered the gene expression in colon cancer, Gastroenterology \& Hepatology from Bed to Bench, 2018, 11, 34-41.

32. C. Li, Y. Jeong and M. Kim, Mammea longifolia Planch. and Triana Fruit Extract Induces Cell Death in the Human Colon Cancer Cell Line, SW480, via Mitochondria-Related Apoptosis and Activation of p53, J. Med. Food, 2017, 20, 485-490.

33. Jin, Yang, Ma, Ma, Ren, Guo, Wang, Zhang, Zhao and Cui, In vivo and in vitro induction of the apoptotic effects of oxysophoridine on colorectal cancer cells via the Bcl-2/Bax/caspase-3 signaling pathway, Oncology Letters, 2017, 14, 8000.

34. C. C. Tsai, Y. S. Li and P. P. Lin, Inonotus obliquus extract induces apoptosis in the human colorectal carcinoma's HCT-116 cell line, Biomedicine \& pharmacotherapy = Biomedecine \& pharmacotherapie, 2017, 96, 1119-1126.

35. M. Youn, J. Kim, Sy, Y. Kim, S. Kim, J. Lee, K. Chai, H. Kim, M. Cui, H. So and K. Kim, Chaga mushroom (Inonotus obliquus) induces G0/G1 arrest and apoptosis in human hepatoma HepG2 cells, World Journal of Gastroenterology, 2008, 14, 511-517.

36. M. J. Youn, J. K. Kim, S. Y. Park, Y. Kim, C. Park, E. S. Kim, K. I. Park, S. S. Hong and R. Park, Potential anticancer properties of the water extract of Inontus obliquus by induction of apoptosis in melanoma B16-F10 cells, Journal of Ethnopharmacology, 2009, 121, 221-228.

37. M. Nomura, T. Takahashi and A. Uesugi, Inotodiol, a lanostane triterpenoid, from Inonotus obliquus inhibits cell proliferation through caspase-3-dependent apoptosis, Anticancer Research, 2008, 28(5A), 2691-2696.

\section{Table}


Table 1

Effects of IOP60b on apoptosis and cell cycle of HT-29 cells

\begin{tabular}{|c|c|c|c|c|c|c|}
\hline \multirow[t]{2}{*}{ Group (mg/mL) } & \multicolumn{3}{|c|}{ Apoptotic cells (\%) } & \multicolumn{3}{|c|}{ Cell cycle distribution (\%) } \\
\hline & Live & Early apoptosis & Late apoptosis & G0/G1 & $\mathrm{G} 2 / \mathrm{M}$ & $\mathrm{s}$ \\
\hline 0 (control) & $92.42 \pm 0.23^{f}$ & $0.40 \pm 0.03^{\mathrm{a}}$ & $0.35 \pm 0.03^{\mathrm{a}}$ & $73.54 \pm 0.40^{\mathrm{a}}$ & $8.00 \pm 0.00^{c}$ & $18.46 \pm 0.40^{\mathrm{e}}$ \\
\hline 0.625 & $80.16 \pm 0.47^{e}$ & $3.55 \pm 0.21^{b}$ & $10.55 \pm 0.01^{\mathrm{b}}$ & $76.42 \pm 0.5^{b}$ & $8.00 \pm 0.00^{c}$ & $15.58 \pm 0.5^{d}$ \\
\hline 1.25 & $73.33 \pm 0.63^{d}$ & $4.34 \pm 0.67^{b}$ & $18.05 \pm 0.02^{c}$ & $79.86 \pm 0.82^{c}$ & $8.00 \pm 0.00^{c}$ & $12.14 \pm 0.82^{c}$ \\
\hline 2.5 & $67.17 \pm 0.50^{c}$ & $5.32 \pm 0.22^{c}$ & $23.11 \pm 0.18^{d}$ & $83.61 \pm 0.6^{d}$ & $6.27 \pm 0.62^{b}$ & $10.12 \pm 0.2^{\mathrm{b}}$ \\
\hline 5 & $54.75 \pm 1.60^{\mathrm{b}}$ & $6.89 \pm 0.83^{d}$ & $28.60 \pm 0.16^{\mathrm{e}}$ & $85.01 \pm 0.6^{d}$ & $5.46 \pm 0.39^{b}$ & $9.53 \pm 0.82^{b}$ \\
\hline 10 & $51.50 \pm 0.44^{a}$ & $7.37 \pm 0.70^{d}$ & $28.81 \pm 0.11^{\mathrm{e}}$ & $90.03 \pm 0.40^{\mathrm{e}}$ & $3.31 \pm 0.63^{a}$ & $6.66 \pm 0.40^{\mathrm{a}}$ \\
\hline
\end{tabular}

\section{Figures}

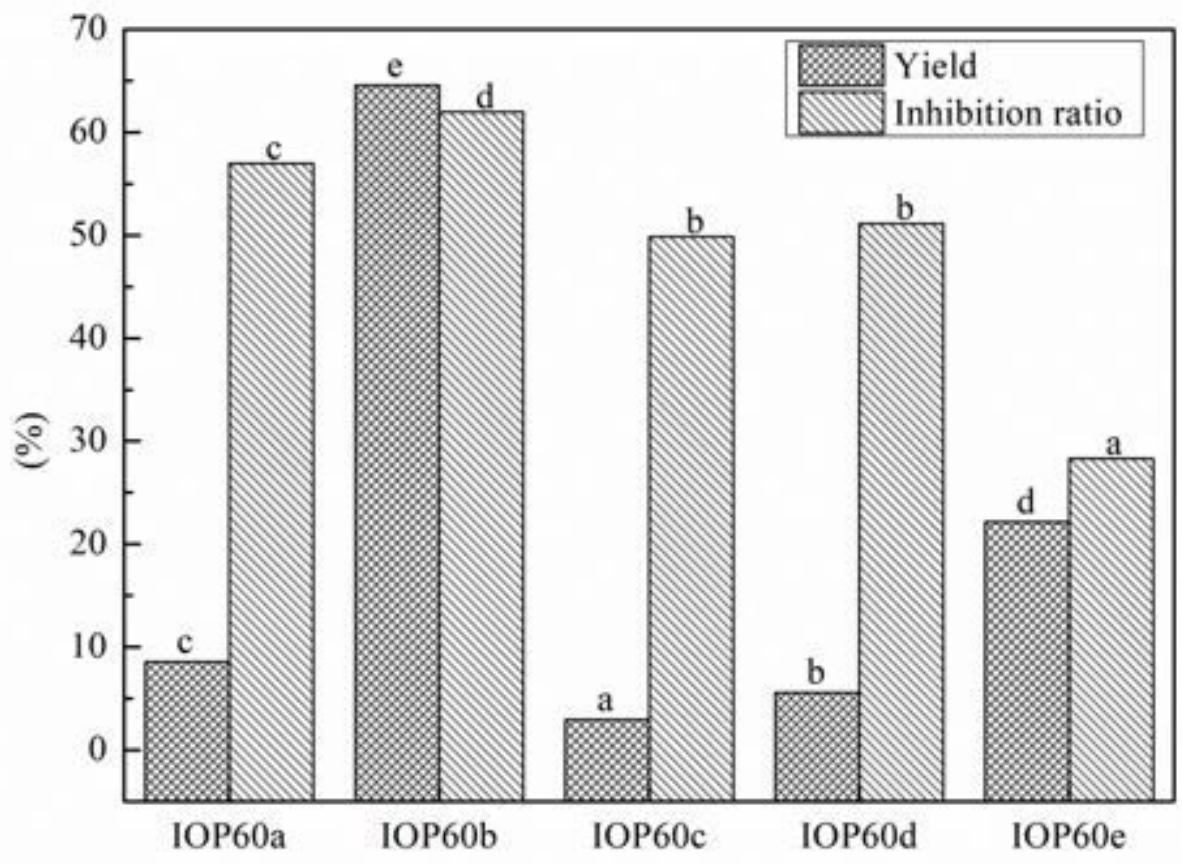




\section{Figure 1}

Yields of polysaccharides with different molecular weight extracted from I. obliquus and their inhibition ratios of HT-29 cells. Superscripts ( $a, b, c, d$, and e) represent significant differences between the substrates $(P<0.05)$.
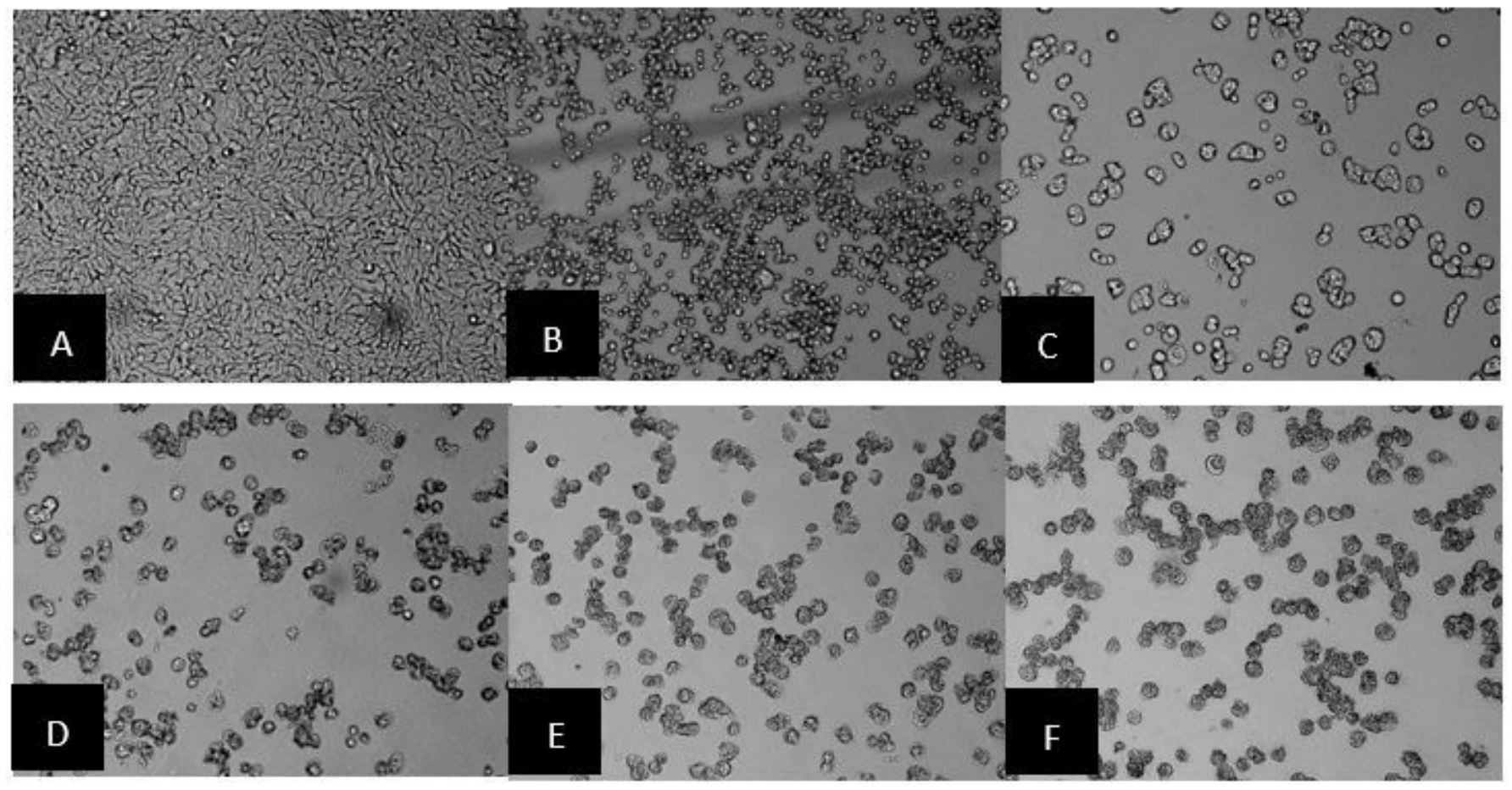

Figure 2

Effects of IOP60b on cellular morphology in HT-29 cells: Cellular morphology was observed under an optical microscopy $(\times 100)$. A, B, C, D, E, F represent the morphology of HT-29 cells after treatment with IOP60b at $0,0.625,1.25,2.5,5$ and $10 \mathrm{mg} / \mathrm{mL}$ concentrations for $48 \mathrm{~h}$, respectively. 


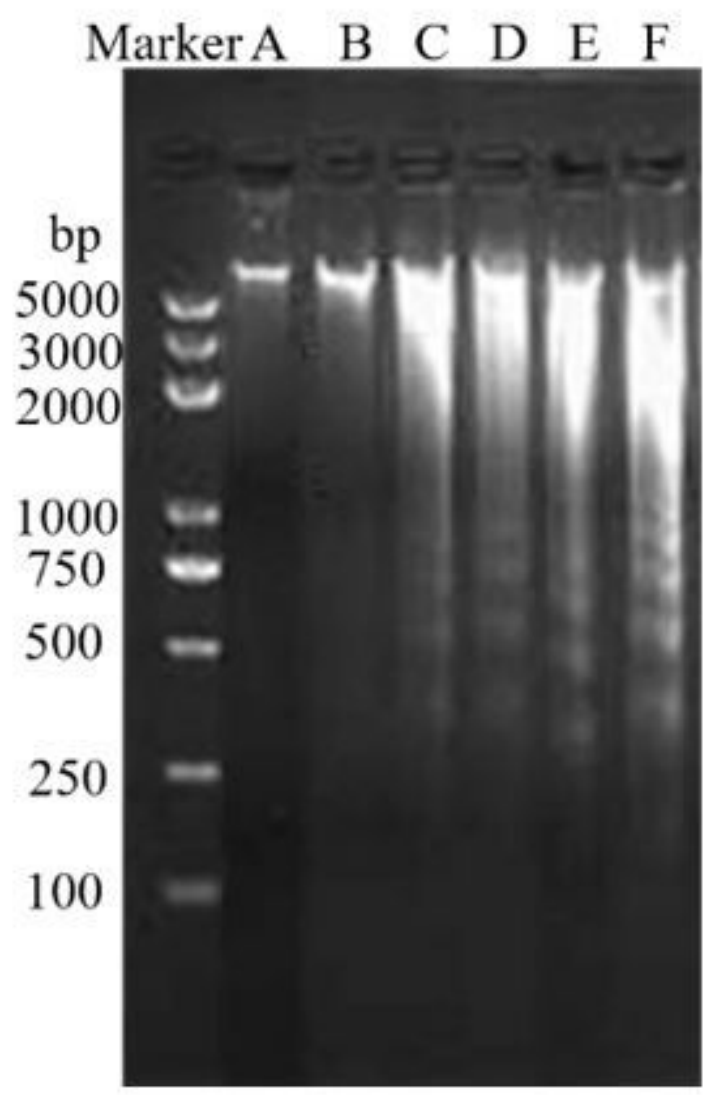

Figure 3

Effects of IOP60b with different concentration on DNA fragmentation in HT-29 cells. Lane A: Control; Lane B: 0.625 mg/mL; Lane C: 1.25 mg/mL; Lane D: $2.5 \mathrm{mg} / \mathrm{mL}$; Lane E: 5 mg/mL; Lane F: $10 \mathrm{mg} / \mathrm{mL}$. 

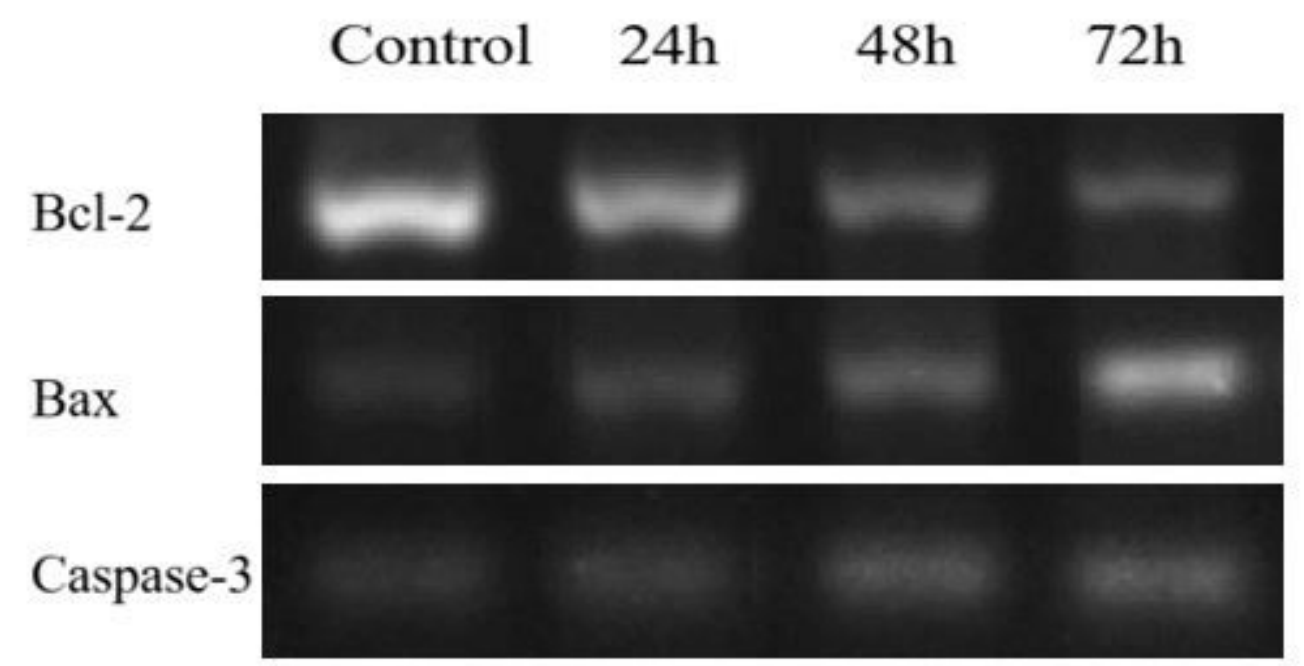

$\beta$-actin
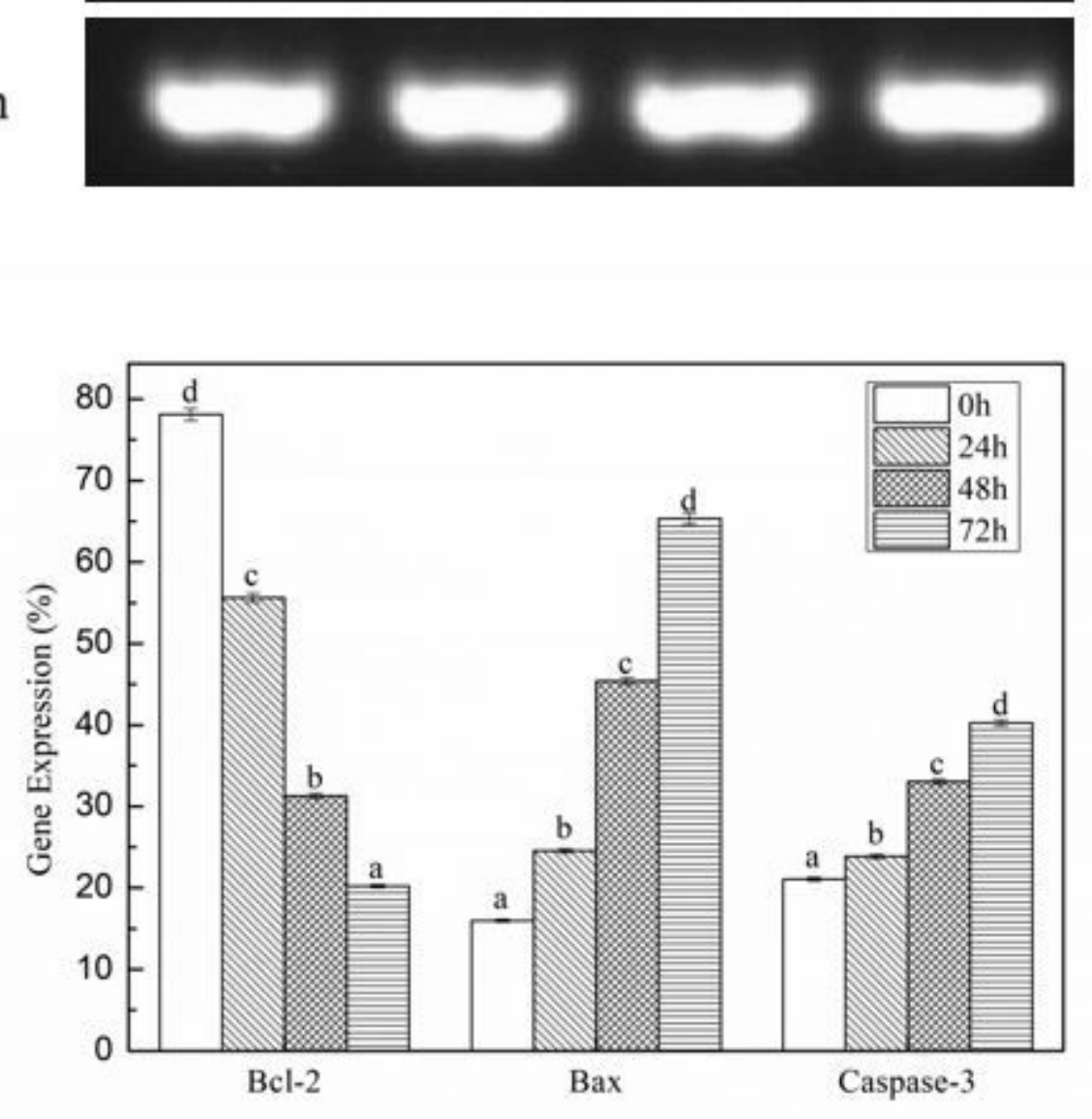

Figure 4

Effects of IOP60b on mRNA of Bcl-2, Bax and Caspase-3 in HT-29 colon cancer cells. Superscripts (a, b, c, and d) represent significant differences between the time-points $(P<0.05)$. 

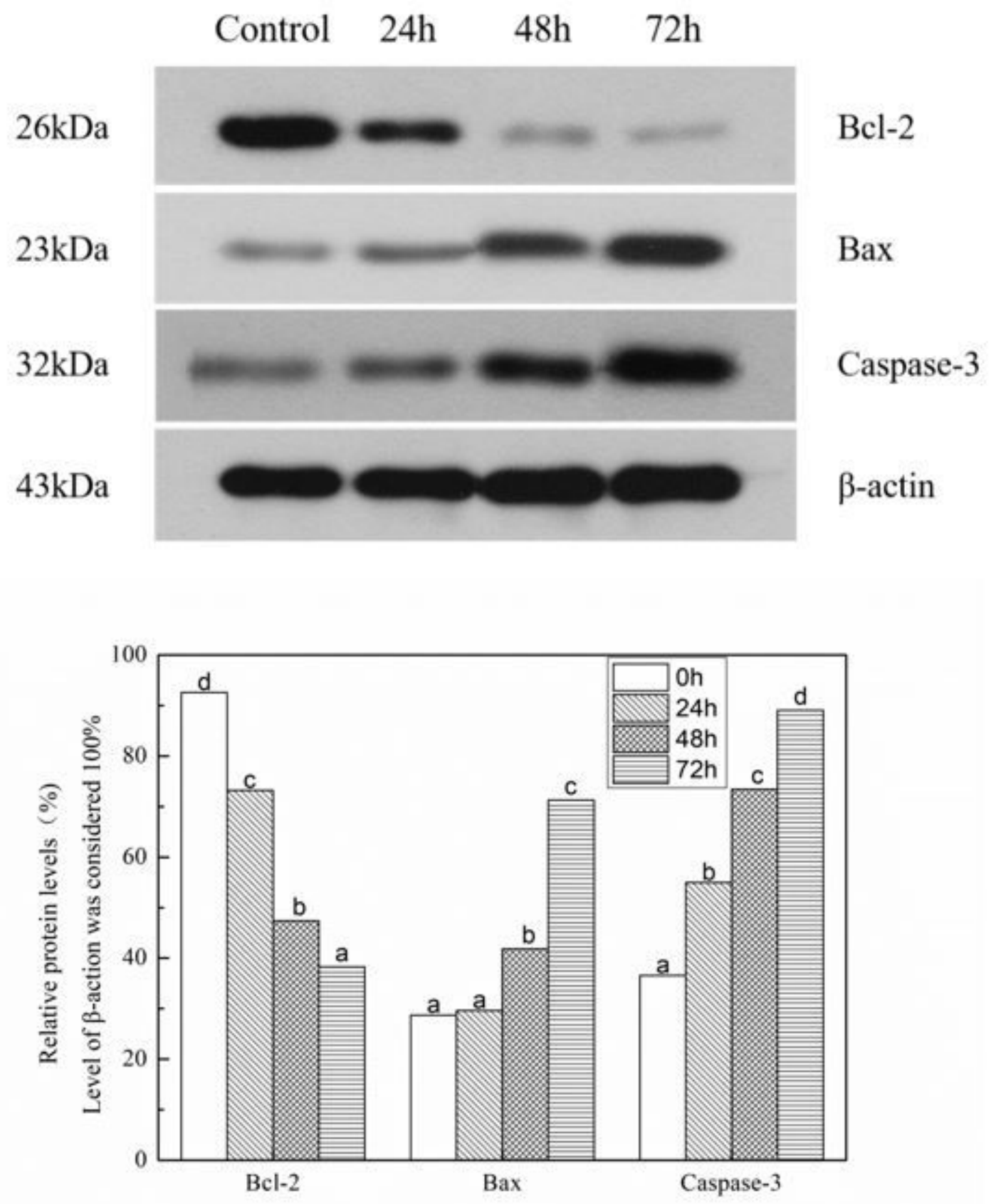

Figure 5

Effects of IOP60b on protein expression of Bcl-2, Bax and Caspase-3 in HT-29 colon cancer cells. Superscripts $(a, b, c$, and d) represent significant differences between the time-points $(P<0.05)$. 